\title{
Cultivo y Transferencia de Blastocistos: ¿La Respuesta?
}

\author{
Juan Luis Giraldo*; Paulo Serafini" ${ }^{* *}$; Antonia Habana*; David Olive ${ }^{* * *}$
}

\section{RESUMEN}

En la década de los noventa el desarrollo de la técnica para cultivar y transferir blastocistos luego de una fertilización in vitro ha reportado beneficios en ciertos aspectos cruciales de esta práctica. El mayor control sobre la incidencia de embarazos múltiples es una de sus principales bondades. El proceso de autoselección al que se someten los embriones ha permitido que se transfieran embriones mas viables y con una mayor capacidad de implantarse en el endometrio. También ha contribuido al desarrollo de una nueva ola en la evaluación y el diagnóstico preimplantación del embrión. Detallados análisis de los fenómenos metabólicos cambiantes en el embrión temprano han permitido la aparición de nuevos medios de cultivo que soportan el crecimiento embrionario in vitro hasta su estado de blastocisto. Estos medios están reemplazando al cocultivo como herramienta preferida para cultivar blastocistos. Sin embargo aun existen interrogantes sobre el mecanismo de acción de los cocultivos y sobre la forma en que algunos de sus efectos benéficos como la producción de factores embriotróficos específicos, puedan ser incorporados a los nuevos medios.

PALABRAS CLAVES: Blastocisto/medịos secuenciales/cocultivo/fertilización in vitro/diagnóstico preimplantación.

\section{SUMMARY}

The development of the technique to cultivate blastocysts has brought many benefits in the practice of in vitro fertilization. The possibility of diminishing the high multiple pregnancy rates associated with these techniques has been one of the most important contributions. The process of in vitro embryo auto-selection has enabled us to transfer more viable embryos with a better possibility of implantation. The culture of blastocysts has contributed, to the new wave of research on preimplantation diagnosis. Detailed analysis of early embryo metabolism has envolved into the development of complex culture media capable to efficiently support embryos to the blastocyst stage. These media are replacing the coculture as the preferred environment to grow blastocysts. However, there are still many questions about the mechanisms of promoting embryo growth and success. Further analysis of the production of embryotrophic factors involved in coculture embryo support should be identified and incorporated for the manufacturing of better media.

KEY WORDS: Blastocyst/sequential media/coculture/In Vitro Fertilization/preimplantation diagnosis.

\section{¿Por qué transferir blastocistos?}

El cultivo del embrión hasta el estado de blastocisto ha cobrado marcada importancia en la práctica de la fertilización in vitro en los últimos años. El interés en el blastocisto se basa en el afán por lograr una sincronización entre el embrión y el medio intrauterino al cual este se transfiere (1). De esta manera se ha intentado hacer de la fertilización in vitro un proceso más cercano a las condiciones fisiológicas en que se dan el desarrollo embrionario temprano y el proceso de implantación.

Al llegar a la pubertad, el ovario humano contiene aproximadamente 300 a 400 mil oocitos primarios.

Fellow, División Medicina Reproductiva e Infertilidad, Departamento de Obstetricia y Ginecología, Universidad de Yale. USA.

Profesor Asociado, División de Medicina Reproductiva e Infertilidad, Departamento de Obstetricia y Ginecología, Universidad de Yale, USA.

Director de la División de Medicina Reproductiva e Infertilidad. Departamento de Obstetricia y Ginecología, Universidad de Yale, USA.
Estos se encuentran detenidos en la primera división meiótica que se inicia desde antes del nacimiento. La ovulación marca la reactivación de la primera meiosis, que culmina con la formación del primer cuerpo polar y del oocito secundario y el comienzo de la segunda división meiótica que se detiene en la etapa de metafase hasta la fertilización. El óvulo comienza entonces su recorrido por la luz tubárica, donde es fertilizado en las primeras 24 horas, generalmente en la porción ampular. La segunda división meiótica se reactiva en el momento en que el espermatozoide penetra la zona pelúcida. Al completar esta segunda meiosis, momento marcado por la extrusión del segundo cuerpo polar, el zigoto o preembrión ingresa a la etapa pronuclear. Los pronúcleos, cada uno con el material genético paterno o materno, se fusionan dando por culminado el proceso de fertilización y origen al embrión como tal.

Aun en el oviducto comienza la división mitótica del embrión. Cuarenta y ocho horas pos-fertilización esté llega a su estado de 4 a 8 células. Hacia el tercer día el embrión forma la mórula, con 16 a 32 células y continúa su división hasta formar el blastocisto luego de 4 a 5 días de haber sido fertilizado. Este último se caracteriza por 
la formación del blastocele y de la masa celular interna que dará origen al feto. En estas condiciones el embrión llega a la cavidad uterina, sale de la zona pelúcida y hacia el sexto o séptimo día se implanta en la superficie endometrial.

Los protocolos clásicos de fertilización in vitro incluyen la transferencia embrionaria luego de 2 ó 3 días de cultivo. Esto somete prematuramente al embrión a un medio intrauterino cuyo grado de hostilidad y receptividad en dicha etapa embrionaria aun es incierto. La transferencia de embriones en la etapa de blastocisto lleva a que el embrión cultivado artificialmente llegue a la cavidad uterina en el momento en que lo haría si hubiera sido concebido in vivo. Esto puede facilitar el intercambio embrión-endometrio y llevar a una optimización del proceso de implantación.

\section{Pros y contras}

La transferencia de blastocistos luego de 5 días de cultivo ha demostrado tener algunas ventajas sobre la transferencia de embriones en el estado de 4 a 8 células, tradicionalmente transferidos luego de 2 ó 3 días de cultivos. Esta modalidad requiere de una logística más elaborada y de un tiempo más prolongado de cultivo que los métodos clásicos, por ende se somete a los embriones a un proceso de selección. Como resultado es posible que sólo los embriones más competentes de la cohorte en cultivo logren llegar al estado de blastocisto. De esta manera no se transfieran embriones destinados a frenar su desarrollo. En resumidas cuentas se transfiere un menor número de embriones pero con mayor posibilidad de sobrevivir e implantarse, logrando un resultado más predecible y una tasa más baja de embarazos múltiples (24). De allí se desprende el hecho de que ocurra un aumento de la baja tasa de implantación de los embriones de clivaje que fluctúa entre un $10-20 \%$, logrando tasas de $25 \%$ e incluso de $45 \%$ y $58 \%$ con el cultivo de blastocistos según lo reportan algunos autores $(5,6)$. Como es de esperarse, ya que el número de embriones transferidos disminuye, las tasas de embarazo siguen siendo similares a las logradas con transferencia de embriones en clivaje pero con disminución en el número de embarazos múltiples.

Como se mencionó antes el ambiente intrauterino es el medio natural del blastocisto más no del embrión en etapa de clivaje. El embrión in vivo llega a la cavidad uterina luego de iniciarse el período de compactación. La exposición prematura de los embriones en etapa de clivaje cultivados in vitro a el medio intrauterino, sumado a los efectos adversos del cultivo como tal son probablemente los responsables de la alta tasa de falla de implantación en dichos ciclos. Mejores resultados en ciclos de fertilización in vitro con transferencia de blastocistos reportados por algunos autores pueden ser debidos a una mejor sincronización entre el embrión y el endometrio (7). Las bajas tasas de formación de blastocisto y de embarazo reportadas con el cultivo de blastocistos en un principio (8-10) son probablemente el resultado del proceso normal de mejoramiento de una técnica pero más que todo del uso de medios de cultivo inapropiados disponibles en ese momento.
Una ventaja adicional del proceso de selección al que son sometidos los embriones cultivados hasta blastocisto radica en el número reducido de embriones que requieren criopreservación (2, 4, 10-12). Es probable que los embriones no competentes frenen su desarrollo y se degeneren antes de formar un blastocisto. En otras condiciones estos serían suceptibles de ser criopreservados en su etapa pronuclear o de clivaje. Este concepto tiene claras implicaciones sobre la problemática ética y de almacenamiento de embriones. Además disminuye los costos de funcionamiento del laboratorio y los problemas médico legales relacionados con el manejo de embriones en criopreservación.

El diagnóstico preimplantación es otro de los beneficiados con el cultivo y posterior tranferencia de embriones en etapa de blastocisto. El tiempo transcurrido entre la etapa de clivaje y la formación del blastocisto permite la biopsia de blastómera y su posterior análisis para toma de decisiones clínicas $(2,4)$. Además en esta etapa se posibilita la biopsia del trofoectodermo con sus posibles ventajas sobre la biopsia de blastómera, evitar la manipulación directa del tejido embrionario y obtener un mayor número de células. El análisis genético se facilita al aumentar el tamaño de la biopsia.

Aparte del análisis genético la posibilidad de desarrollar métodos de diagnóstico no invasivo aplicables al blastocisto se erige como una nueva herramienta en la selección de los mejores embriones para ser transferidos (13). Es de anotar que el genoma del embrión se activa luego de la etapa de 4 a 8 células (etapa de clivaje) (14), por lo cual el análisis de marcadores embrionarios previo a esta etapa refleja las condiciones heredadas del oocito y no las propias del embrión. Algunas técnicas pueden ser útiles en la evaluación de los embriones para predecir y determinar la viabilidad embrionaria. El análisis de la tasa de clivaje ha arrojado resultados contradictorios en cuanto a su utilidad. Algunos autores han reportado que esta tiene una relación directamente proporcional con la tasa de formación de blastocistos. A su vez encontraron que los blastocistos formados a partir de embriones con una baja tasa de clivaje tienen menor posibilidad de implantarse y generar un feto viable que los que se forman a partir de embriones con alta tasa de clivaje. (15). Sin embargo otros autores no han encontrado una relación significativa entre la tasa de clivaje y la obtención de blastocistos viables (Serafini).

El análisis del metabolismo energético es otro parámetro que se erige como uno de los posibles métodos de evaluación y selección. Se ha encontrado que los embriones de ratón con mayor utilización de glucosa y menor producción de lactato son los de mejor pronóstico y tienen la mayor tasa de desarrollo fetal (16). Sin embargo esta técnica aún no es viable para la aplicación clínica en humanos.

Hasta el momento, la morfología del blastocisto se erige como el mejor marcador de su viabilidad. Se ha reportado que el número de blastocistos con un blastocele completamente expandido, con células poligonales bien definidas en su trofoectodermo y con una masa celular interna única, es mayor en las mujeres que logran un embarazo que en las que no lo logran $(5,12)$. 
Teniendo en cuenta las ventajas del cultivo y posterior transferencia de blastocistos se pueden definir ciertas situaciones en las que sería indicado recurrir a esta técnica $(11,17)$ : pacientes con mayor riesgo de complicaciones relacionadas con embarazos múltiples como las pacientes con malformaciones uterinas, pacientes con varias fallas de implantación en ciclos previos, pacientes que requieren una biopsia de sus embriones para selección genética preimplantación y pacientes en quienes se sospechan defectos en la calidad de sus oocitos y/o embriones.

Por otro lado el cultivo y transferencia de blastocistos tiene ciertos reparos. Es posible que las condiciones de selección in vitro sean diferentes a las condiciones in vivo. Esto implica la posibilidad de que un embrión que in vitro no logró desarrollarse hasta el estado de blastocisto podría haberlo logrado in vivo, dando lugar a un feto viable. Esta teoría puede ser apoyada por estudios que demuestran que las tasas de éxito en ciclos con embriones congelados en la etapa de clivaje y en etapa de blastocisto son similares $(18,19)$. Así también, no todos los embriones que logran llegar a la etapa de blastocisto in vitro tienen la capacidad de implantarse y dar origen a un feto viable (9).

Aunque el desarrollo de métodos de evaluación y selección del blastocisto son una posibilidad clara y llamativa, aun no se han consolidado como procedimientos prácticos y con resultados clínicos claros. Actualmente los parámetros morfológicos y la expansión del blastocele son los criterios de selección más prácticos. La producción de Gonadotropina Coriónica Humana (HCG) parece tener un pico de secreción muy tardío para poder ser utilizada como herramienta de selección de los blastocistos más aptos para transferir (20).

La evaluación de la calidad embrionaria basados en características morfológicas tiene algunas deficiencias. Su carácter subjetivo genera dudas sobre su capacidad para predecir el potencial de desarrollo futuro de los embriones. En etapas tempranas el porcentaje de fragmentación y la apariencia de las blastómeras son características morfológicas importantes. Además la presencia de blastómeras multinucleadas en la etapa de 2 células es uno de los parámetros más indicativos del trastorno futuro en el desarrollo de dicho embrión (21). Sin embargo en etapas medianas a tardías esta evaluación morfológica se dificulta. En la mórula y en el blastocisto en expansión el conteo de células por microscopía de luz convencional es inexacto y además los métodos con sondas fluorescentes (22) para diferenciar entre citoplastos acelulares o vacúolas y blastómeras acelulares no son prácticos para la aplicación clínica. Aún se requiere también el desarrollo de métodos viables para la evaluación específica de la masa celular interna.

No es de ignorar el aumento en la complejidad y costo de los métodos de cultivo necesarios para lograr la transferencia de blastocistos. Se requieren como primera medida de 2 a 3 días más de cultivo. Además la necesidad de introducir medios de cultivo secuenciales más complejos y costosos o líneas celulares para el establecimiento de cocultivos. El cocultivo no sólo aumenta el costo y la complejidad sino que introduce la posibilidad de contaminación de los embriones a partir de infecciones no detectadas en las células de la monocapa, sean estas de origen animal o humano. Sin embargo, cabe anotar que si se tiene en cuenta la disminución en la tasa de embarazos múltiples que se logra con la transferencia de blastocistos, el costo integral en la atención de un grupo de pacientes puede incluso disminuir con respecto al de un grupo con transferencia de embriones en etapa de clivaje.

Por último el proceso de selección al que se someten los embriones en el cultivo prolongado hasta la etapa de blastocisto que se erige como una de las bondades de esta práctica es un arma de doble filo. Llegarán las pacientes cuyos embriones en clivaje no den origen a ningún blastocisto. No es tarea fácil explicarles que es probable que ninguno de esos embriones transferidos más tempranamente hubiese dado origen a un feto viable ya que un proceso de selección similar al del cultivo se habría dado en el ambiente intrauterino. Esta situación genera un sentimiento de fracaso y duda de parte de la paciente, que se debe tener en cuenta antes de embarcarse en el cultivo de blastocistos. Sin embargo algunas de estas pacientes sienten que por lo contrario, es una ventaja no tener que soportar varios días más de espera angustiante y exámenes innecesarios para conocer el resultado de unos embriones en estado de clivaje que fueron transferidos y que estaban predestinados a frenar su desarrollo (Serafini).

\section{Cocultivos}

El método más indicado para el cultivo de blastocistos aún genera controversias. Los factores embriotróficos específicos requeridos para el desarrollo óptimo del blastocisto in vitro aún no han sido determinados. Estos factores pueden transmitir al blastocisto una capacidad de desarrollarse in vitro similar a la que tiene in vivo y con seguridad serán objeto primordial de estudio en los años por venir. Lograr medios de cultivo que similen las condiciones in vivo podrá aumentar las tasas de implantación y embarazo a niveles como los demostrados por Buster et al (1985) (23), quien con blastocistos humanos desarrollados in vivo y obtenidos por lavado uterino logró tasas de implantación y embarazo de $60 \%$ por blastocisto transferido. Cabe anotar que Buster en su grupo de pacientes utilizó madres subrogadas y no pacientes con problemas de infertilidad y esto se puede constituir en un sesgo.

Tanto los medios únicos tradicionales como los cocultivos con una monocapa de células somáticas han sido utilizados en el cultivo de embriones desde su estado de zigoto hasta el de blastocisto. El uso de medios tradicionales, tanto simples como complejos, ha arrojado una tasa de desarrollo de blastocisto a partir de preembriones con 2 pronúcleos por debajo del 50\% (8-10, 24). Además las tasas de embarazo han sido más bajas aún que las logradas con la transferencia de embriones en su etapa de 4 a 8 células. Esto no sólo demuestra que no son el método ideal de cultivo, sino que se debe diferenciar entre la capacidad de un medio de permitir el desarrollo in vitro hasta el estado de blastocisto y su capacidad de lograr blastocistos viables.

Desde 1960 se inició la experimentación con cocultivos en embriones de ratón. Diferentes células somáticas en 
diferentes especies se han estudiado hasta llegar a la aplicación del cocultivo en embriones humanos. Se ha experimentado con células epiteliales tubáricas, células endometriales humanas y bovinas, células del cúmulo y de la granulosa y células Vero, derivadas del epitelio renal en simios. Estas últimas han arrojado tasas de desarrollo hasta blastocisto que sobrepasan el 60\% (2526). Otros autores también reportaron alentadores resultados iniciales con el cocultivo al evidenciar mayores tasas de desarrollo de blastocistos y de embarazo que con el uso de los medios tradicionales (27-28), e inćluso al evidenciar también mayores tasas de fertilización (29). Sin embargo, los resultados en la experimentación con cocultivos han sido inconstantes. Varios ensayos clínicos randomizados no han mostrado una diferencia clara entre el resultado del cultivo con monocapa de células somáticas o sin ella (22-30). Las diferencias en los componentes del cultivo y las técnicas de laboratorio entre los distintos ensayos hacen difícil aún la posibilidad de sacar conclusiones sobre las ventajas y desventajas de los cocultivos.

El efecto del cocultivo sobre el desarrollo embrionario no parece ser propio de células o especies específicas. Los resultados comparables de las distintas células somáticas humanas e incluso algunas de origen animal, sugieren que el efecto no se da por la creación de un ambiente similar al del oviducto (31). Se han postulado algunos mecanismos de acción del cocultivo. Uno de ellos es la función detoxificadora del medio por las células de la monocapa, que eliminan las embriotoxinas potenciales. Es posible que las células somáticas del cocultivo dada su capacidad de metabolizar la glucosa en el medio sean reguladoras de la concentración de glucosa, logrando niveles tolerables para el embrión en sus diferentes etapas (32). Por último se cree que las células de la monocapa pueden secretar sustancias embriotróficas como el TGF-a (Transforming Growth Factor), TGF-b1, PDGF-a (Platelet Derived Growth Factor) e IGF-I y II (Insulin Like Growth Factor) y de esta manera soportar el desarrollo embrionario hasta la formación del blastocisto.

En conclusión aún falta evidencia clínica que permita evaluar la verdadera utilidad del cocultivo, ante todo su utilidad en el mejoramiento de las tasas de embarazo. Se están haciendo avances en el desarrollo de medios más afines con el metabolismo cambiante del embrión. La identificación e incorporación de los factores embriotróficos producidos por las células somáticas de los cocultivos a los medios nuevos será un avancé importante en el mejoramiento de los resultados clínicos en la fertilización in vitro.

\section{Fisiología embrionaria y medios secuenciales}

El estudio de la fisiología embrionaria preimplantación ha permitido establecer que el embrión tiene dos períodos que marcan una diferencia clara en la forma como funciona y se regula su metabolismo. Antes de formar la mórula las células embrionarias se están dividiendo pero se mantienen separadas unas de otras en lo que se conoce como el período pre-compactación. En este período cada célula funciona independientemente y no existen meca- nismos de regulación sofisticados como los que se encuentran en los organismos multicelulares. Al formar la mórula las células no sólo se dividen sino que forman nexos entre ellas, entrando al período post-compactación, que coincide con la llegada del embrión a la cavidad uterina. De esta manera el embrión requiere y por ende desarrolla mecanismos de regulación y homeostasis que le permiten controlar su ambiente interno (33).

Los requerimientos metabólicos del embrión de menos de 8 células (etapa pre-compactación) son marcadamente diferentes a sus requerimientos luego de esta etapa, a medida que se acerca al estado de blastocisto (etapa post-compactación). El embrión en clivaje presenta bajos niveles de biosíntesis, poca actividad respiratoria y una capacidad limitada para utilizar la glucosa como fuente de energía (34-36). A su vez estas tres facetas se ven aumentadas a medida que se acerca más al estado de blastocisto.

Estos cambios del metabolismo dictan que la estrategia a seguir para obtener embriones con alta capacidad de desarrollarse e implantarse es la de acomodar los medios de cultivo a necesidades cambiantes durante su desarrollo hasta la etapa de blastocisto (33). Los medios de cultivo utilizados en la práctica clínica de fertilización in vitro en humanos se dividen en simples y complejos. Los simples son soluciones balanceadas con sales asociadas a una fuente de energía de carbohidratos como el piruvato, lactato o la glucosa. Los complejos contienen además aminoácidos, algunas vitaminas y por lo general son complementados con suero. Los más utilizados son el HTF (Human Tubal Fluid) y el Ham's F-10 y a pesar de que el primero es un medio simple y el segundo un medio complejo, los resultados obtenidos son similares en cuanto a desarrollo embrionario y tasas de embarazo. Esto se debe probablemente a que los embriones son transferidos al útero durante su segundo o tercer día de cultivo, antes de que la activación de su genoma y el inicio de su actividad biosintética permitan la verdadera influencia sobre el embrión por los diferentes medios de cultivo. Sin embargo, aunque los resultados son comparables, sólo un 10-15\% de los embriones transferidos logran producir un feto viable. Es probable que estos pobres resultados sean consecuencia de ignorar las verdaderas necesidades metabólicas del embrión en cultivo, además del hecho de que estas cambian de una etapa a otra durante su desarrollo.

La glucosa ha tomado papel protagónico entre los conocimientos actuales sobre el metabolismo del embrión. Existe una tendencia a eliminar la glucosa de los medios de cultivo embrionario que se basa en la premisa de que el embrión en etapa de clivaje parece utilizar amino ácidos y ácido carboxílico, mas no la glucosa como fuente de energía (37). Esta última puede incluso causar un freno en el desarrollo del embrión en etapa de clivaje cuando se incluye en los medios de cultivo simples (38), al disminuir su capacidad oxidativa. Además parece ser que in vivo el oocito y el zigoto están expuestos a un ambiente con muy baja concentración de glucosa (39). Esto se da por las bajas concentraciones de glucosa en el líquido tubárico y por la actividad metabólica marcada de las células del cúmulo, que alrededor del 
oocito y del embrión temprano consumen la glucosa y secretan lactato y piruvato.

Sin embargo, la glucosa tiene un papel importante en el metabolismo del embrión luego de sus primeras etapas de clivaje y desde poco antes de la etapa de compactación, cuando ocurre la activación del genoma embrionario. Luego de esta etapa el embrión in vivo ya no está rodeado de las células del cúmulo y se expone a concentraciones mayores de glucosa. Además con la activación del genoma embrionario, la actividad biosintética del embrión aumenta y por ende este requiere de glucosa en ciertas etapas de la síntesis de ácidos nucléicos (40-41). Por esta razón aunque se ha logrado cultivar embriones hasta el estado de blastocisto en medios sin glucosa (38), estos son de menor calidad y viabilidad cuando se comparan con los cultivados en medios con glucosa (42).

Aparte de los cambios en el metabolismo energético del embrión también hay cambios a nivel de los requerimientos de nitrógeno. Los amino ácidos a nivel embrionario no sólo son importantes reguladores de la función celular sino que también pueden conferir al embrión una mayor capacidad de desarrollo. Se ha reportado una concentración muy baja de amino ácidos esenciales, excepto glutamina, en el oviducto de ratones hembras. Este grupo de amino ácidos adicionados a los medios de cultivo antes del estado de 8 células se asocia con una disminución en la viabilidad de los embriones de ratón. Sin embargo luego del estado de 8 células, los amino ácidos esenciales generan un aumento en la tasa de desarrollo de la masa celular interna. A su vez los amino ácidos no esenciales han demostrado tener un efecto acelerador del desarrollo, aumentando la viabilidad en los embriones en estado 8 células. Estos últimos se han relacionado con un efecto estimulador de la formación del blastocele y de la masa celular interna (43). De esta manera se entiende que el medio de cultivo embrionario debe contener amino ácidos no esenciales y glutamina en las primeras 48 horas de cultivo embrionario y seguido de un medio que contenga tanto amino ácidos no esenciales como esenciales.

Recientemente el desarrollo y uso de medios de cultivo secuenciales y sin suero, más similares a los líquidos del tracto genital femenino, han demostrado resultados más alentadores. Se han reportado con el uso de medio G1 desde la etapa de zigoto hasta la etapa de 8 células y del medio G2 desde la etapa de 8 células hasta la de blastocisto, tasas de desarrollo de blastocisto de $66 \%$, tasas de implantación de $45 \%$ y tasas de embarazo de $63 \%$ (1). Estos medios exponen al embrión de menos de 8 células a concentraciones más bajas de glucosa y a amino ácidos no esenciales, mientras que al embrión de más de 8 células lo exponen a mayores concentraciones de glucosa y a una combinación de amino ácidos esenciales y no esenciales. Además no son suplementados con suero sino con albúmina sérica humana, lo que disminuye la inducción de patrones alterados de crecimiento atribuidos a los medios con suero (44).

En conclusión se ha logrado a través de los años una mejor comprensión del medio ambiente embrionario in vivo y su traducción a la tecnología in vitro ha marcado una línea en el desarrollo de las técnicas de reproducción asistida. Hasta ahora el cultivo de blastocistos ha permitido un mayor control sobre la alta tasa de embarazos múltiples y ha abierto un amplio horizonte en lo que es el diagnóstico embrionario. Desafortunadamente, el aumento en las tasas de embarazo que en algún momento se esperó con esta técnica aún no se ha hecho realidad. Es posible que el perfeccionamiento de los medios de cultivo con la inclusión de factores embriotróficos aún por identificarse lleven en el futuro a tasas de embarazo mucho mayores que las que hoy logramos. Sin embargo nunca debemos olvidar que hay ciertos factores inherentes a los gametos que manipulamos que todavía desconocemos y que muy probablemente no son suceptibles de corregir aún con los medios de cultivo más sofisticados.

\section{BIBLIOGRAFIA}

1. Gardner, D., et al. Culture and transfer of human blastocyst increases implantation rates and reduces the need for multiple embryo transfers. Fertility and Sterility, 1998; 69: 84-88

2. Edwards, R. and P. Hollands. New advances in human embryology: implications of the preimplantation diagnosis of genetic disease Human Reproduction. 1988; 3: 549-556.

3. Plachot, M. Co-culture of embryos and feeder cells. Human Reproduction, 1996; 1: 35-42.

4. Plachot, M., et al. Chromosome investigations in early life. II. Human preimplantation embryos. Human Reproduction, 1987; 2: 29-35.

5. Alves da Motta, E., et al. High implantation and pregnancy rates with transfer of human blastocysts developed in preimplantation stage one and blastocyst media. Fertility and Sterility, 1998; 70: 659-663.

6. Scholtes, M. and G. Zeilmaker. A prospective, randomized study of embryo transfer results after 3 or 5 days of embryo culture in in vitro fertilization. Fertility and Sterility, 1996; 65: 12451248 .

7. Gardner, D. Mammalian embryo culture in the absence of serum or somatic cell support. Cell Biol Int, 1994; 18: 1163-1179.

8. Hardy, K., A. Handyside, and R. Winston. The human blastocyst: cell number, death and allocation during late preimplantation development in vitro. Development, 1989; 107: 597-604
9. Bolton. V., M. Wren, and J. Parsons. Pregnancies after in vitro fertilization and transfer of human blastocysts. Fertility and Sterility, 1991; 55: 830-832.

10. Dokras, A., I. Sargent, and D. Barlow. Human blastocyst grading: an indicator of developmental potential? Human Reproduction, 1993; 8: 2119-2127.

11. Olivennes, F., et al. Four indications for embryo transfer at the blastocyst stage. Human Reproduction, 1994; 9: 2367-2373.

12. Quinn, P. Use of coculture with cumulus cells in insemination medium in human in vitro fertilization (IVF). J Assist Reprod Genet, 1994; 11: 270-277:

13. Gardner, D. and H. Leese. Assessment of embryo viability prior to transfer by the non-invasive measurement of glucose uptake. J. Exp. Zool., 1987. 242: p. 103-105.

1.. Braude, P., V. Bolton, and S. Moore. Human gene expression first occurs between the four and eight cell stages of preimplantation development. Nature, 1988. 332: p. 459-461.

15. McKiernan, S. and B. Bavister. Timing of development is a critical parameter for predicting successful embryogenesis. Human Reproduction, 1994; 9: 2123-2129.

16. Lane, M. and D. Gardner. Selection of viable mouse blastocysts prior to transfer using metabolic criterion. Human Reproduction, 1996; 11: 1975-1978. 
17. Ménézo, Y., et al. Coculture of embryos on Vero cells and transfer of blastocysts in humans. Human Reproduction, 1992; 7(1): 101-106.

18. Queenan, J., et al. Transfer of cryopreserved-thawed pre-embryos in a natural cycle or a programmed cycle with exogenous hormonal replacement yields similar pregnancy results. Fertility and Sterility, 1994; 62: 1690-1697.

19. Kaufman, R., et al. Cocultured blastocyst cryopreservation: experience of more than 500 transfer cycles. Fertility and Sterility, 1995; 64: $1125-1129$

20. Bavister, B. and D. Boatman. The neglected human blastocyst revisited Human Reproduction, 1997; 12: 1607-1610.

21. Kligman, L., et al. The presence of multinucleated blastomeres in human embryos is correlated with chromosomal abnormalities. Human Reproduction, 1996; 11: 1492-1498.

22. Van Blerkom, J. Development of human embryos to the hatched blastocyst stage in the presence or absence of a monolayer of Vero cells. Human Reproduction, 1993; 8: 1525-1539.

23. Buster, J., et al. Biologic and morphologic development of donated human ova by nonsurgical uterine lavage. Am. J. Obstet. Gynecol., 1985; 153: 211-217.

24. Winston, N., et al. The incidence of abnormal morphology and nucleocytoplasmic ratios in 2-, 3- and 5-day human pre-embryos. Human Reproduction, 1991; 6: 17-24.

25. Ménézo, Y., J. Guerin, and I. Czyba. Improvement of human early embryo development in vitro by coculture on monolayers of Vero cells. Biol. Reprod., 1990; 42: 301-306.

26. Turner, $\mathrm{K}$. and E. Lenton. The influence of Vero cell culture on human embryo development and chorionic gonadotrophin production in vitro. Human Reproduction, 1996; 11: 1966-1974.

27. Wiemer, K., et al. In- vitro development and implantation of human embryos following culture on fetal bovine uterine fibroblasts. Human Reproduction, 1989; 4: 595-600.

28. Wiemer, K., et al. Embryonic morphology and rate of implantation of human embryos following co-culture on bovine oviductal epithelial cells. Human Reproduction, 1993; 8: 97-101.

29. Bongso, T.. et al. Blastocyst transfer in human in vitro fertilization: the use of embryo co-culture. Cell Biol. Int., 1994; 18: 1181-1189.

30. Sakkas, D., et al. Comparison of results after in vitro fertilized human embryos are cultured in routine medium and in co-culture on Vero cells: a randomized study. Fertility and Sterility, 1994; 61: 521-525.
31. Ménézo, Y., D. Sakkas, and L. Janny. Co-culture of the early human embryo: factors affecting human blastocyst formation in vitro. Microscopy Research and Technique, 1995; 32: 50-56.

32. Bavister, B. Culture of preimplantation embryos: facts and artifacts. Human Reproduction Update, 1995; 1: 91-148.

33. Gardner, D. and M. Lane. Culture and selection of viable blastocysts: a feasible proposition for human IVF. Human Reproduction Update, 1997; 3: 367-382.

34. Epstein C. and S. Smith. Amino acid uptake and protein synthesis in preimplantation mouse embryos. Dev. Biol., 1973; 33: 171-184.

35. Mills, R. and R. Brinster. Oxygen consumption of preimplantation mouse embryos. Exp. Cell Res., 1967; 47: 337-344.

36. Brinster, R. and J. Thomson. Development of eight cell mouse embryos in vitro. Exp. Cell Res, 1996: 42: 308-315.

37. Leese, $\mathrm{H}$. Metabolism of the preimplantation mammalian embryo. Oxf. Rev. Reprod. Biol, 1991; 13: 35-72.

38. Quinn, P. Enhanced results in mouse and human embryo culture using a modified human tubal fluid medium lacking glucose and phosphate. J. Assist. Reprod. Genet., 1995. 12: 97-105.

39. Gardner. D., et al. Environment of the preimplantation human embryo in vivo: metabolite analsis of oviduct and uterine fluids and metabolism of cumulus cells. Fertility and Sterility, 1996; 65: 349-353

40. Morgan, M. and P. Faik. Carbohydrate metabolism in cultured animal cells. Biosci. Rep. 1981; 1: 669-686.

41. Reitzer, L., B. Wice, and D. Kennel. The pentose cycle: control and essential function in HeLa cell nucleic acid synthesis. J. Biol. Chem. 1980; 255: 5616-5626

42. Gardner, D. and M. Lane. Alleviation of the "2-cell block" and development to the blastocyst of CF1 mouse embryos: role of amino acids. EDTA and physical parameters. Human Reproduction. 1996; 11: 2701-2712.

43. Lane, M. and D. Gardner. Differential regulation of mouse embryo developments and viability by amino acids. J. Reprod. Fertil., 1997; 109: $153-164$

44. Thompson, J., et al. Lamb birth weight following transfer is affected by the culture system used for pre-elongation development of embryos. Biol. Reprod., 1995: 53: 1385-1391.

\title{
IMPORTANTE
}

\section{LA REFERENCIA BIBLIOGRAFICA DE LA REVISTA COLOMBIANA DE OBSTETRICIA Y GINECOLOGIA ES:}

\author{
Rev Colomb Obstet Ginecol
}

\author{
DEBE CITARSE DE ESTA MANERA, YA QUE CORRESPONDE \\ A LA NORMATIZACION Y RECONOCIMIENTO DE \\ LA PUBLICACION A NIVEL INTERNACIONAL.
}

